\title{
A Study of Voluntary Environmental Management Practices among Apparel Manufactures in Sri Lanka: Case Study Approach
}

\author{
Hemachandra D.W.K.* \\ University of Sri Jayewardenepura, Nugegoda, Sri Lanka \\ *kinkini2009@gmail.com
}

\begin{abstract}
Textile and apparel industry contributes to $27 \%$ of industrial sector in Sri Lanka. This sector contributes to earn the largest export income for Sri Lanka during the last two decades. There are different types of textile and apparel producers such as knitted apparel manufactures, woven apparel manufactures, weaving operators, fabric producers, washing and dyeing operators etc. With the increasing share of contribution to the national economy the level of industrial pollution has also recorded a significant level of increases. Specially, wash garments and dyeing garments have contributed to significant level of water pollution in any country. Solutions are provided either in terms of mandatory regulations or voluntary measures. Some of the leading textile and apparel manufactures in Sri Lanka practice voluntary environmental mechanisms to protect the environment.

This study examines different voluntary environmental management practices among textile and apparel manufactures in Sri Lanka. Case study approach is used to achieve study objectives. Ten cases were selected from the list of registered apparel manufactures at the Board of Investment in Sri Lanka. Ten factories represent both ISO 14001 certified factories and non-certified factories. They were randomly selected from the list, which is after identifying certified and non certified companies separately. Data were collected based on indepth interviews using a structured questionnaire. Each factory is considered as a separate facility as unit of analysis. Interviews are conducted with senior level manager who is familiar with production process and compliances in the factory. Data were presented using graphs, tables and charts. Study found some common environmental systems in the factories which have ISO 14001. The most common practices are waste management systems, water recycling, energy use monitoring, and establishment of environmental management systems at the factory. In additionally, the study also examined the reasons for adopting such environmental management systems by the producers. Accordingly, buyers' pressure and owners' pressure are found to be the main factors for this adoption decision.
\end{abstract}

Keywords: Voluntary environmental practices, Apparel and textile industry 